\title{
Triamcinolone for diabetic retinopathy
}

\author{
Triancinolona no tratamento da retinopatia diabética
}

$\mathbf{T}$ he current therapeutic approach to diabetic retinopathy, based on the high level of scientific evidence, includes drugs administered via intraocular injection into the vitreous cavity associated or not to laser photocoagulation of the retina, besides a multidisciplinary approach for systemic metabolic control. The treatment is indicated in the proliferative form of the disease and/or diabetic macular edema (the main cause of visual loss). The ETDRS - Early Treatment Diabetic Retinopathy Study - has defined the laser treatment strategies in the diabetic retinopathy according to the classification, assessing the effects of panphotocoagulation at earlier stages and macular photocoagulation for macular edema ${ }^{1,2}$.

As for drugs, we have some available for exclusive use in the eye (ranibizumab and aflibercept) and the ones used in an "off label" way with extensive global experience as for the effectiveness (triamcinolone and bevacizumab). Invariably, patients are involved in the discussion about the choice of drug, convenience, power, cost and side effects. Among them, an important factor for access to treatment is the cost, being it the great competitive advantage of the "off label" drugs.

The triamcinolone approach in this editorial is due to our view that it is an excellent treatment choice for selected patients due to the properties it has regarding the pathophysiology of diabetic retinopathy, in addition to the low cost of application. It is believed that the mechanism of action of triamcinolone in diabetic retinopathy produces an antiinflammatory effect not only by reducing cellular mediators of inflammation, but also by stabilizing the blood-retinal barrier $^{3,4}$. On the other hand, the diabetic macular edema is thought to be a multifactorial disease with the action of inflammatory and VEGF (Vascular Endothelial Growth Factor) factors. Studies have shown the superiority of anti-VEGF vs Laser, and currently there is pharmacological treatment indication of the diabetic macular edema in patients with an edema involving the center of the macula, defined as the central subfield thickness e" 250 microns and as visual acuity as Snellen equivalent of 20/32 to 20/320. However, evidence has shown that interleukin 8 (IL-8) may play an important role in cases refractory to anti-VEGF, and that triamcinolone could be an option for said cases. The presence of IL-8 supports the hypothesis that non-responsive patients to anti-VEGF seem to have the preponderance of inflammatory effects in the genesis of the macular edema. Joen et al. showed low levels of VEGF in the aqueous humor at the moment of injection of triamcinolone, inferring that only the reduction of VEGF was not enough to cure the macular edema ${ }^{6}$.

The DRCR net group in a phase 3 study did not observe any difference in the visual acuity between intravitreal triamcinolone plus laser treatment $(n=203)$ and laser monotherapy $(n=186)$ after one year. However, the subgroup of pseudophakic eyes treated with triamcinolone and laser showed better results in the visual acuity compared to only laser ${ }^{7}$. Another study in this group showed a similar effect of triamcinolone and ranibizumab in pseudophakic patients or with minimal change of crystalline ${ }^{8}$. Thus, triamcinolone can be considered the drug of first choice in patients with pseudophakic diabetic macular edema and who did not present ocular hypertension and/or glaucoma9 .

Pioneering studies showed a favorable effect of intravitreal triamcinolone as an adjuvant to the laser treatment in patients with proliferative diabetic retinopathy and macular edema in relation to those treated only with laser therapy ${ }^{10,11}$. This finding was confirmed in a multicenter study of DRCR net, and currently the triamcinolone may be an option in patients with proliferative diabetic retinopathy and macular edema undergoing laser treatment ${ }^{12}$.

Recently, it was demonstrated that not only triamcinolone raises the intraocular pressure (IOP). Continuous treatment with ranibizumab may increase the risk of raising the IOP or the need for an ocular hypotensive ${ }^{13}$. We must be judicious regardless of the drug chosen and conduct a closer post operative evaluation. While most of these complications are transient and/or treatable, the retinologist must consider them when assessing the risks and benefits of the treatment, and it is important to report to the patients the possibility of adverse effects of these medications.

Therefore, the use of triamcinolone in diabetic retinopathy can be considered in selected patients, and a careful analysis of cost-effectiveness is imperative for adhesion to the treatment. It gives a more universal access to the drug benefits in the treatment of this multifactorial disease.

Otacílio de Oliveira Maia Júnior Assistant at Hospital São Rafael - Fundação Monte Tabor, Salvador - BA. 


\section{ReFERENCES}

1. Treatment techniques and clinical guidelines for photocoagulation of diabetic macular edema. Early Treatment Diabetic Retinopathy Study Report Number Early Treatment Diabetic Retinopathy Study Research Group. Ophthalmology. 1987;94(7):761-74.

2. Techniques for scatter and local photocoagulation treatment of diabetic retinopathy: Early Treatment Diabetic Retinopathy Study Report no. 3. The EarlyTreatment Diabetic Retinopathy Study Research Group. Int Ophthalmol Clin. 1987;27(4):254-64. 3.Wilson CA, Berkowitz BA, Sato Y, Ando N, Handa JT, de Juan E Jr. Treatment with intravitreal steroid reduces blood-retinal barrier breakdown due to retinal photocoagulation. Arch Ophthalmol. 1992;110(8):1155-9.

4. Funatsu H, Noma H, Mimura T, Eguchi S, Hori S. Association of vitreous inflammatory factors with diabetic macular edema. Ophthalmology. 2009;116(1):73-9.

5. Wells JA, Glassman AR, Ayala AR, et al; Diabetic Retinopathy Clinical Research Network. Aflibercept, bevacizumab, or ranibizumab for diabetic macular edema. N Engl J Med. 2015;372(13):1193-203.

6. Jeon S, Lee WK. Effect of intravitreal triamcinolone in diabetic macular edema unresponsive to intravitreal bevacizumab. Retina. 2014;34(8):1606-11.

7. Diabetic Retinopathy Clinical Research Network, Elman MJ, Aiello LP, Beck RW, Bressler NM, Bressler SB, Edwards AR, Ferris FL 3rd, Friedman SM, Glassman AR, Miller KM, Scott IU, Stockdale CR, Sun JK. Randomized trial evaluating ranibizumab plus prompt or deferred laser or triamcinolone plus prompt laser for diabetic macular edema. Ophthalmology. 2010 Jun;117(6):1064-1077.e35.

8. Elman MJ, Bressler NM, Qin H, Beck RW, Ferris FL 3rd, Friedman SM, GlassmanAR, Scott IU, Stockdale CR, Sun JK; Diabetic Retinopathy Clinical Research Network. Expanded 2-year follow-up of ranibizumab plus prompt or deferred laser or triamcinolone plus prompt laser for diabetic macular edema. Ophthalmology. 2011;118(4):609-14.

9. Dewan V, Lambert D, Edler J, Kymes S, Apte RS. Cost-effectiveness analysis of ranibizumab plus prompt or deferred laser or triamcinolone plus prompt laser for diabetic macular edema. Ophthalmology. 2012;119(8):1679-84.

10. Bandello F, Polito A, Pognuz DR, Monaco P, Dimastrogiovanni A, Paissios J. Triamcinolone as adjunctive treatment to laser panretinal photocoagulation for proliferative diabetic retinopathy. Arch Ophthalmol. 2006;124(5):643-50.

11. Maia OO Jr, Takahashi BS, Costa RA, Scott IU, Takahashi WY. Combined laser and intravitreal triamcinolone for proliferative diabetic retinopathy and macular edema: one-year results of a randomized clinical trial. Am J Ophthalmol. 2009;147(2):291-7 e2.

12. Diabetic Retinopathy Clinical Research Network, Googe J, Brucker AJ, Bressler NM, Qin H, Aiello LP, Antoszyk A, Beck RW, Bressler SB, Ferris FL 3rd, Glassman AR, Marcus D, Stockdale CR. Randomized trial evaluating short-term effects of intravitreal ranibizumab or triamcinolone acetonide on macular edema afterfocal/grid laser for diabetic macular edema in eyes also receiving panretina photocoagulation. Retina. 2011 Jun;31(6):1009-27.

13. Bressler SB, Almukhtar T, Bhorade A, Bressler NM, Glassman AR, Huang SS, Jampol LM, Kim JE, Melia M; for the Diabetic Retinopathy Clinical Research Network Investigators. Repeated intravitreous ranibizumab injections for diabetic macular edema and the risk of sustained elevation of intraocular pressure or the need for ocular hypotensive treatment. JAMA Ophthalmol. 2015 Feb 26. doi:10.1001/ jamaophthalmol.2015.186. [Epub ahead of print] 